\title{
Surgical Decompression of Pudendal Nerve by Transperineal Approach Using a Balloon Probe
}

\author{
Eric de Bisschop ${ }^{1,2, *}$, Rajeshree Nundlall ${ }^{2}$ \\ ${ }^{1}$ Perineology, Clinique La Casamance, Fr-13400 Aubagne, France \\ ${ }^{2}$ Angiology, 55 avenue des Goums, Fr-13400 Aubagne, France
}

\begin{abstract}
Since 2009 may to 31 january 2012, 512 patients (371 females, 141 males) have benefited from a pudendal nerve (PN) decompression by transperineal approach using a ballon probe. These patients had clinical symptoms of pudendal neuralgia. Neurophysiological tests based on the staged sacral reflexes, on ultrasound investigations of pudendal vessels and on a pelvic floor ultrasounds evoked a zone of compressive hyperpressure at the level of the axis infrapiriformis area-ischiorectal fossa. All of these 512 patients, injection block at the level of the infrapiriformis area appeared positive between 1 to 9 months. Patients were known for this pathology since many years. Among these 512 patients, 66 had already PN decompression, 27 by transgluteal approach, 36 by transvaginal ( + )/transischiorectal $\left({ }^{\Uparrow}\right)$ approach and 3 by transperineal approach (Shakik extended) but without clinical efficiency.

All of these 512 patients, surgical decompression was done by transperineal approach using a balloon probe.

Surgical methodology, post-op follow up and results are reported hereby, which appear quite successful with few risks to make worse the pathology and no risk on pelvic static.
\end{abstract}

Keywords Pudendal Nerve, Pudendal Neuralgia, Staged Sacral Reflexes, Compressive Hyperpressure, Infrapiriformis Area-Ischiorectal Fossa Axis, Probe With Balloon

\section{Introduction}

Pudendal neuralgia is pain and/or functional signs in one or more of the territories of the PN.

The pudendal nerve can undergo many lesional phenomena throughout his pathway, intra-or extra-spinal (fig. $1)$.

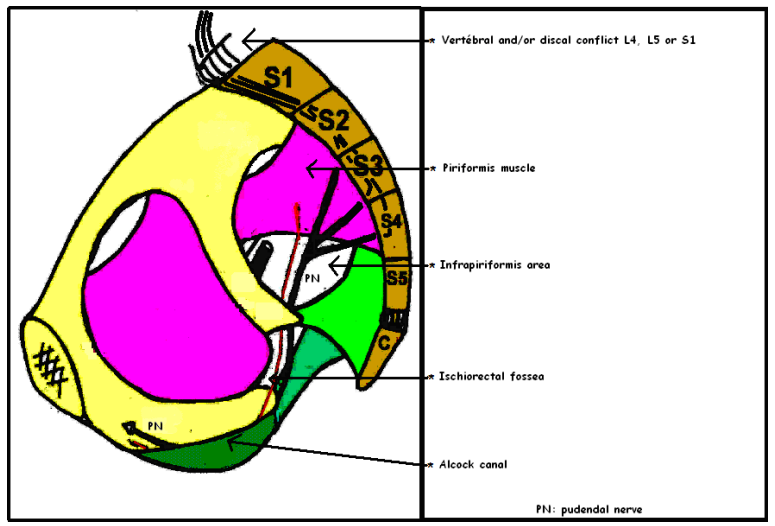

Figure 1. Hight-risk areas of the pudendal nerve

\footnotetext{
* Corresponding author:
}

rajeshree@free.fr (Eric de Bisschop)

Published online at http://journal.sapub.org/ajmms

Copyright (C) 2012 Scientific \& Academic Publishing. All Rights Reserved
The 512 patients selected had a conflict at the level of the infra-piriformis-ischiorectal fossa axis. Conflicts at the piriformis muscle and / or nerve root L4, L5 and S1 were discarded. Electroneuromyographic investigation correlated with pelvic-perineal ultrasound (tissue structure) is more reminiscent of a phenomenon of a tissue hyperpressure than a canal syndrome.

\section{Anatomical Recall (Fig. 2)}

The PN is a mixed nerve taking its origin at the $\mathrm{S} 2, \mathrm{~S} 3$ and S4 roots, with a possible contribution of S1. Then, the NP passes beneath the sacrospinous ligament (SSL). The inferior rectal nerve (IRN), the first collateral PN, born before the coming of the ischiorectal fossa (IRF), does not go under the falciform process (FP) or in the Alcock canal (AC). It will innervate the dorsal quadrant of the anal sphincter (AS). The PN truncal pathway, became perineal nerve (PEN), continues under the FP and the AC (duplication of the fascia of the Obturator internus). It will innervate the ventral quadrant of AS[1-2].

The levator ani nerve (LAN) runs up the anterior coccygeal muscle. It thus does not pass under the SSL or under the FP and thus avoids the AC. It innervates, among other things, the pubococcygeus muscle (PCM).

Note that the PN has many anatomical variations: 
After dissection of the body 7[1-2]: The origin of the IRN is in all cases before entering the ischiorectal fossa (IRF) with a direct path to the posterior of the anal canal, can passes under/throught or above the SSL. Then it runs in the lateral space of the ischiorectal fossa nerve. It never passes in the AC (duplication of the fascia of the Obturator internusl). After dissection of 37 bodies[3], it is found from a trunk under the SSL in $56.2 \%, 11 \%$ in two trunks, 2 trunks with 1 IRN perforating the SSL in $11 \%, 3$ trunks with a IRN does not pierce SSL in the $9.5 \%$ and $12.3 \%$ in three trunk.

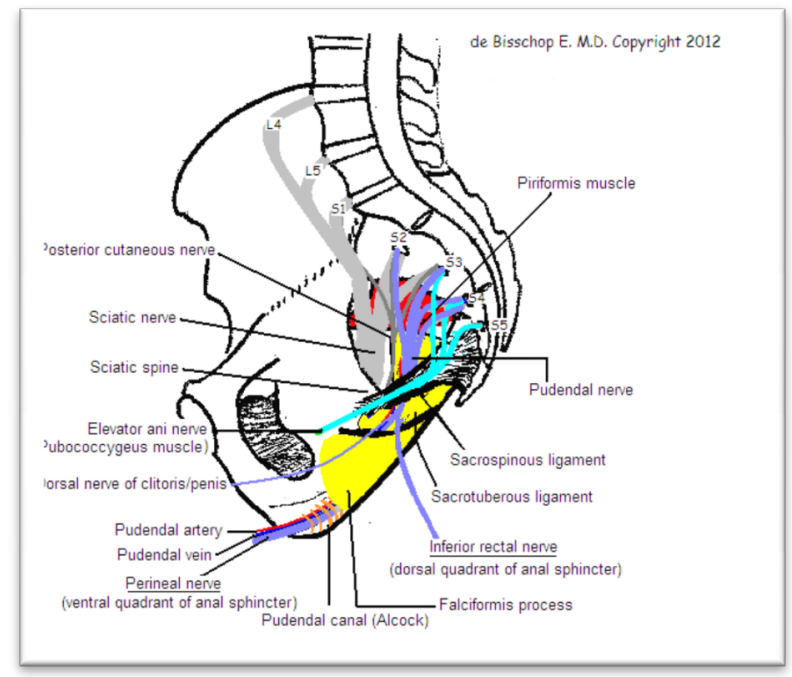

Figure 2. Anatomy of pelvic perineal nerve

\section{Clinical Diagnosis}

The diagnosis is clinical, confirmed by the electrophyiology, the pelvic-perineal Doppler ultrasound and a positive infiltrative test.

Table 1. describes the clinical signs of the 512 operated patients.

Table 1. clinical signs of the 512 selected patients

\begin{tabular}{|c|c|c|}
\hline $\begin{array}{c}\text { clinical signs of the 512 selected } \\
\text { patients }\end{array}$ & $\begin{array}{c}\text { Females } \\
(\%)\end{array}$ & $\begin{array}{c}\text { Males } \\
(\%)\end{array}$ \\
\hline $\begin{array}{c}\text { Burning feeling : anus, perineal, } \\
\text { labial, clitoris, penis, inguinal and } \\
\text { urethral }\end{array}$ & 85,9 & 80,1 \\
\hline Sensation of intrarectal foreign body & 25,9 & 16,3 \\
\hline Erectil dysfunction & & 29,1 \\
\hline Deep dyspareunia & 25,1 & \\
\hline Sciatica & 21,4 & 23,4 \\
\hline Feeling of warmth posterior thigh & 19,4 & 18,4 \\
\hline Pallakiuria & 15,4 & 0,9 \\
\hline Monoparesis & 9,4 & 7,9 \\
\hline $\begin{array}{c}\text { Persistent Sexual Arousal syndrome } \\
\text { or Restless Genital Syndrome }\end{array}$ & 5,4 & 1,2 \\
\hline $\begin{array}{c}\text { Loss of sensation of micturition, } \\
\text { defecation }\end{array}$ & 1,1 & 0,7 \\
\hline
\end{tabular}

About Persistent Sexual Arousal syndrome or Restless Genital Syndrome, it is usually women complain of sudden and frequent feelings of genital arousal, weird sensations at the clitoris, vagina, labia and sometimes the anal region. Note this symptom could exist on girls aged under 10 years. For men, it is usually spontaneous repetitive painful ejaculations in the day.

On all patients studied, we did not recorded anal/urethral denervation, therefore we did not notice a neurogenic urinary ou fecal incontinence.

Note

\section{Material and Method}

Since May 2009, 512 patients (371 women, 141 men) were selected for surgical decompression of the pudendal nerves. These patients had clinical signs of pudendal neuralgia. Electroneuromyographic investigations based on the staged sacral reflexes[4] and on pelvic floor ultrasounds [5-6] evoked a compressive hyperpressure at the level of the infrapiriformis area-ischiorectal fossa axis. Of all these 512 patients, truncal infiltration performed at the infra-piriform area has been positive over periods ranging from 1 to 9 months. Patients were known for this disease for several years. Among these 512 patients, 27 had previously benefited from decompression of PN by trans-gluteal[7], 36 by trans-vaginal[8] and 3 by trans perineal approach (Shafik extended)[9] but no clinical efficacy.

The average age was 49 years ranging from 21 years to 87 years.

\section{Decompression Techniques}

In 1992, Shafik[10] began the PN decompression by transperineal approach to open the AC. This technique was used for anal incontinence pudendal origin but were not associated with pelvic-perineal pain.

Robert by trans-gluteal approach[7] cut the SSL and the sacrotuberous ligament.

Bautrant by transvaginal approach[8] for women and transischiorectal approache for men cuts the SSL.

Beco[9] by the same surgical approach than Shafik but extends the opening to SSL.

\section{Surgical Procedure}

- Vertical incision between the anus and the ischial tuberisity

- Opening the ischiorectal fossa and the infrapiriformis area with dressing forceps

- Introducing the balloon probe in the IPA. Filling the balloon with $5 \mathrm{ml}$ of saline. This maneuver is repeated 3 or 4 times

- Narrowing of the balloon then withdrawal of the probe

- Digital location of the pudendal nerve trunk and complete release of the trunk and its collateral with the finger 
- Verification of freedom of the AC

- Flushing openings

- Skin closure

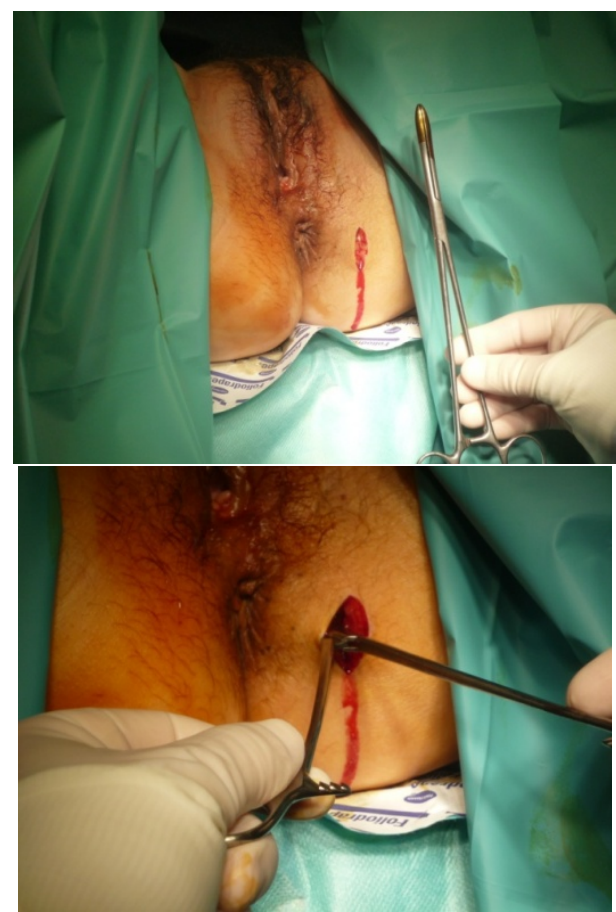

Figure 3. Vertical incision between the anus and the ischial tuberisity and opening the ischiorectal fossa and the infrapiriformis area with dressing forceps

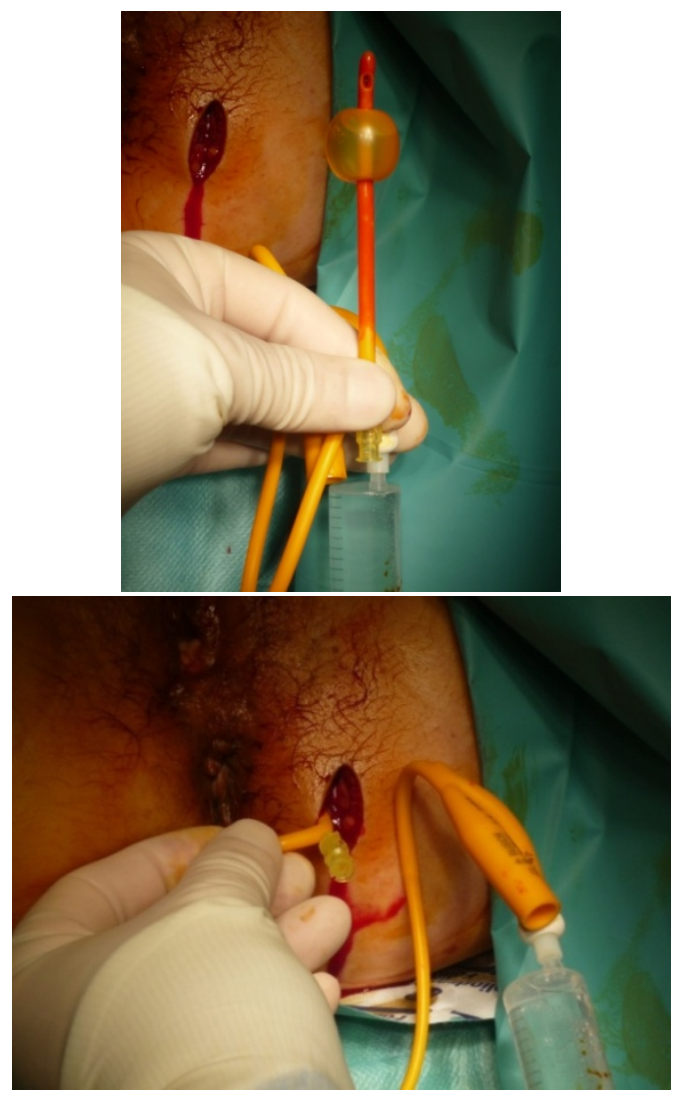

Figure 4. Introducing the balloon probe in the IPA. Filling the balloon with $5 \mathrm{ml}$ of saline. This maneuver is repeated 3 or 4 times

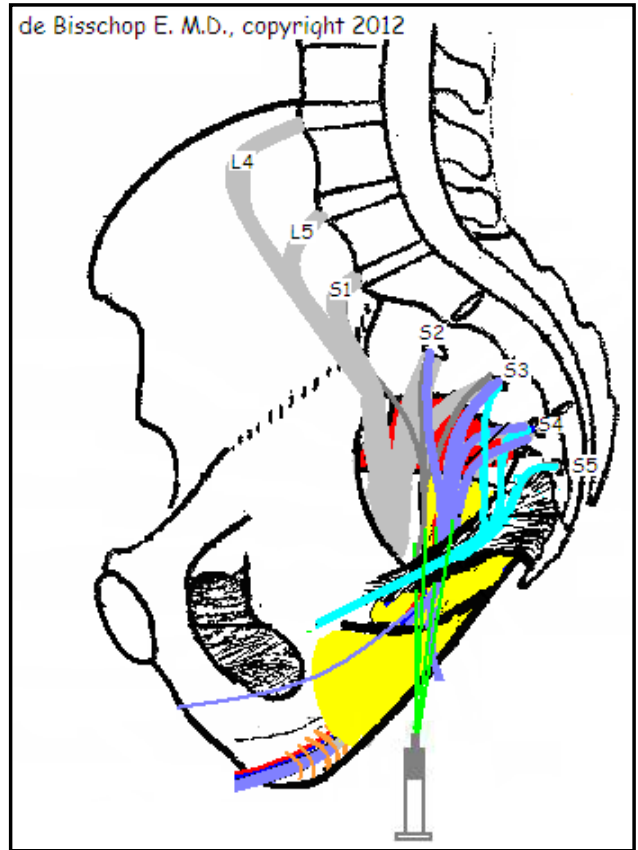

Figure 5. schematization of establishment of a balloon probe
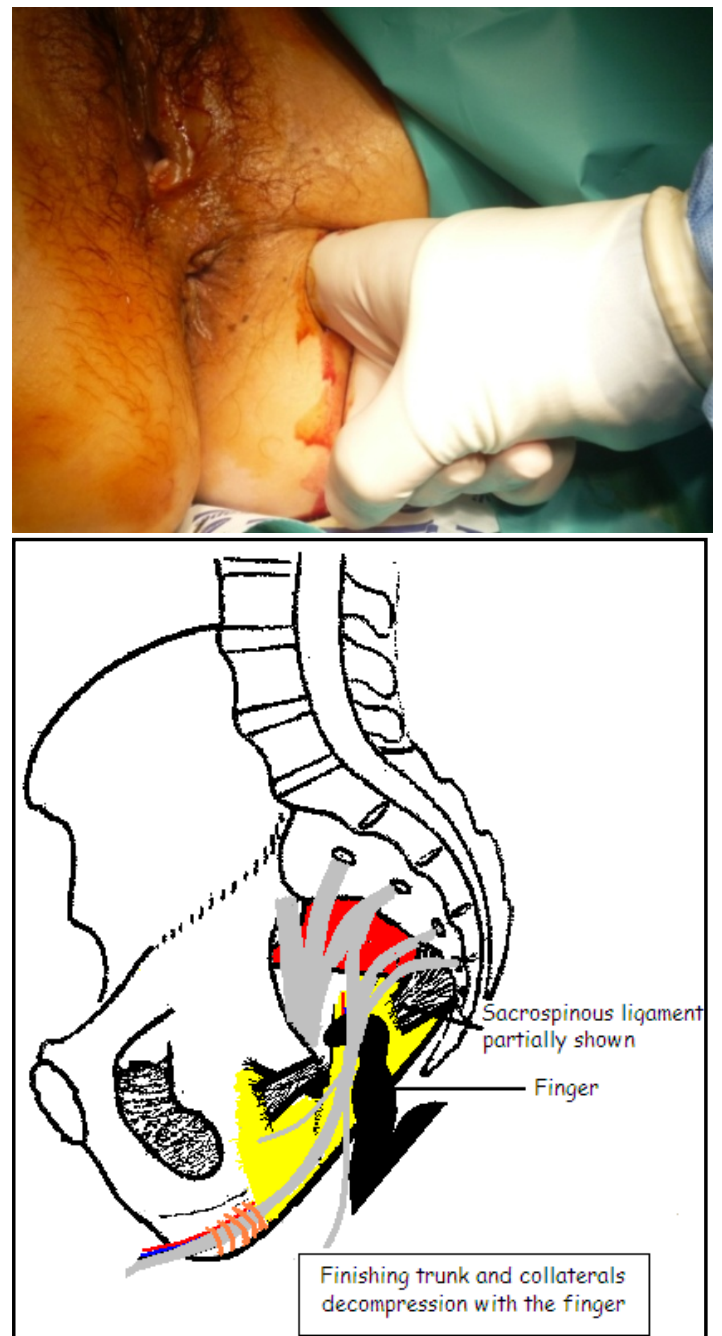

Figure 6. digital location of the nerve trunk and complete release of the trunk and its collateral with the finger 


\section{Postoperative}

Out of Surgery to $\mathrm{J} 1$ or $\mathrm{J} 2$ with return home

\section{Complications}

Gluteal hematoma in $11,7 \%$ (60 patients)

Note the appearance of urinary frequency in $9.2 \%$ of cases (47 patients) associated with urinary incontinence in $4.3 \%$ of cases ( 22 patients) during the 48 hours postoperative.

\section{Results}

The pain assessment was done by VAS (visual analog scale) compared with preoperative pain.

The results correspond to positive patients became asymptomatic or significant reduction of pain with a VAS less than $80 \%$ of the initial value.

At $\mathrm{D}+1$ day $77 \%$, at $\mathrm{D}+1$ month $84 \%$, at $\mathrm{D}+3$ months $89 \%$, at $\mathrm{D}+9$ months $91 \%$ and $\mathrm{D}+12$ months $92 \%$ of asymptomatic patients or significant reduction in pain.

No worsening was reported.

\section{Advantages}

- No ligament section so no risk of destabilization of the pelvic girdle and piriformis syndrome.

- No blind ligament section so no risk of injury or section of the PN and / or EAN

- Rapid clinical improvement (77\% at day 2$)$

- No risk of postoperative fibrosis

- Little or no risk of aggravating the pathology pudendal

\section{Discussion}

Considering the absence of pain in patients operated by Shafik, we hypothesized that the decompression of the PN in the AC was not justified in pudendal neuralgia. The results with $89 \%$ positive results at three months seem to confirm that the $\mathrm{AC}$ is responsible for little or no pain in the pudendal neuralgia.

\section{Conclusions}

This new surgical method of PN decompression appears to have encouraging results with little risk of aggravating the pudendal pathology and safely on the pelvic floor.

\section{REFERENCES}

[1] Spinosa J-P, de Bisschop E, Laurençon J, Kuhn G, Dubuisson J-B, Riedederer B-M. Les réflexes sacrés étagées dans l'étude anatomique de la névralgie pudendale: validation anatomique. Rev Med Suisse 2006;2:2416-2421.

[2] Spinosa J-P, de Bisschop E, Laurençon J, Kuhn G, Riedederer B-M. Differential staged sacral reflexes allow a localization of pudendal neuralgia. Pelviperineoly 2009;28.

[3] Pasuk M, Patcharin S, Pdhyasak V. Anatomical study of the pudendal nerve adjacent to the sacrospinous ligament. Clin Anat. 2005 Apr;18(3):200-205.

[4] de Bisschop E, Bautrant E. Nouveaux concepts d'explorations électrophysiologiques du nerf pudendal dans le cadre de la névralgie pudendale. Electrophysiologie de diagnostic. Electrophysiologie per-opératoire. Pelvimag 2006;55:12-4.

[5] Nundlall de Bisschop R. Intérêt de l'écho-doppler pelvi-périnéal. 2006

http://www.pudendalsite.com/Dr-debisschop4.html

[6] Nundlall de Bisschop R. Preliminary study on Doppler ultrasonography of internal Pudendal Vessels in pudendal neuralgia. 2006 ; http://www.perineology.com/files/dopplernundlal.pdf

[7] Robert R, Brunet C, Faure A, Lehur P-A, Labat J-J, Bensignor $\mathrm{M}$, et al. La chirurgie du nerf pudendal lors de certaines algies périnéales : évolution et résultats. Chirurgie 1993-1994; $119:$ 535-9.

[8] Bautrant E, de Bisschop E, Vaini-Elies V, Massonnat J, Aleman I, Buntinx J et al. La prise en charge moderne des névralgies pudendales. A partir d'une série de 212 patientes et 104 interventions de décompression. J Gynecol Obstet Biol Reprod (Paris) 2003, 32:705-712.

[9] Beco J, Climov D, Bex M. pudendal nerve decompression in perineology: a case series BMC surgery 2004 4:15.

[10] Shafik A. Pudendal canal decompression in the treatment of idopathic fecal incontinence. Dig Surg 1992;9:265-271. 